\title{
Site-specific characterization of heat-induced disulfide rearrangement in beta-lactoglobulin by liquid chromatography-mass spectrometry
}

\author{
Chengkang $\mathrm{Li}^{1}$, Kasper Engholm-Keller ${ }^{1}$, Marianne N. Lund ${ }^{1,2^{*}}$ \\ ${ }^{1}$ Department of Food Science, Faculty of Science, University of Copenhagen, Rolighedsvej 26, 1958 \\ Frederiksberg, Denmark. \\ ${ }^{2}$ Department of Biomedical Sciences, Faculty of Health and Medical Sciences, University of \\ Copenhagen, Blegdamsvej 3, 2200 Copenhagen N, Denmark \\ *Corresponding author: Marianne N. Lund, tel.: +4535333547, e-mail address: mnl@,food.ku.dk
}

\section{Contents}

Supplementary method Detailed criteria of manual disulfide annotation

Figure S1 LC-MS/MS relative quantification of a native (A) Cys6-Cys120, and a nonnative, (B) Cys6-Cys6 disulfide-linked $\alpha$-lactalbumin peptide

Table S1 The approximate peak areas of Cys-containing peptides

Table S2 Distributions of $\beta$-LG molecules in different aggregated states after different heat treatments

Table S3 Distributions of $\beta$-LG molecules in different aggregated states after different heat treatments with addition of urea 


\section{Supplementary method}

In the case when a disulfide bond linked two peptides, each of the peptides was divided into two parts, centered on the Cys residue: The "N-term" comprising the sequence from the Nterminus to the Cys residue and the "C-term" covering the sequence after the Cys residue to the C-terminus. The peaks in the $\mathrm{MS}^{2}$ spectra were matched to the theoretical $\mathrm{m} / \mathrm{z}$ values of fragmentation ions (b- and y-ions) at various charge states at the at their potential retention time(s) that were identified in the $\mathrm{MS}^{1}$ spectrum according to the $\mathrm{m} / \mathrm{z}$ value of individual precursor disulfide-linked peptide from the raw data. Assuming there are " $n$ " amino acids in either the "N-term" or "C-term" part of the peptide (Figure SA), if $\mathrm{n} \geq 3$, at least $\mathrm{n} / 2$, for $\mathrm{n}$ being an even number, or (n-1)/2, for $n$ being an odd number, isotopically resolved independent fragment peaks of $b$ - and $y$ - ions from $b_{2}$ to $b_{n}$ or $y_{2}$ to $y_{n}$ were required; if $n>6$, at least three consecutive amino acids in the peptide sequence were further needed for confident identification of both peptides. In addition, the linker type and location were confirmed by the fragment ions including at least one part of the first peptide, along with the linker, Cys residue, and the complete second peptide. For example, $y_{n_{C-\text { term }}+1}$ or $b_{n_{N-t e r m}}+1$.

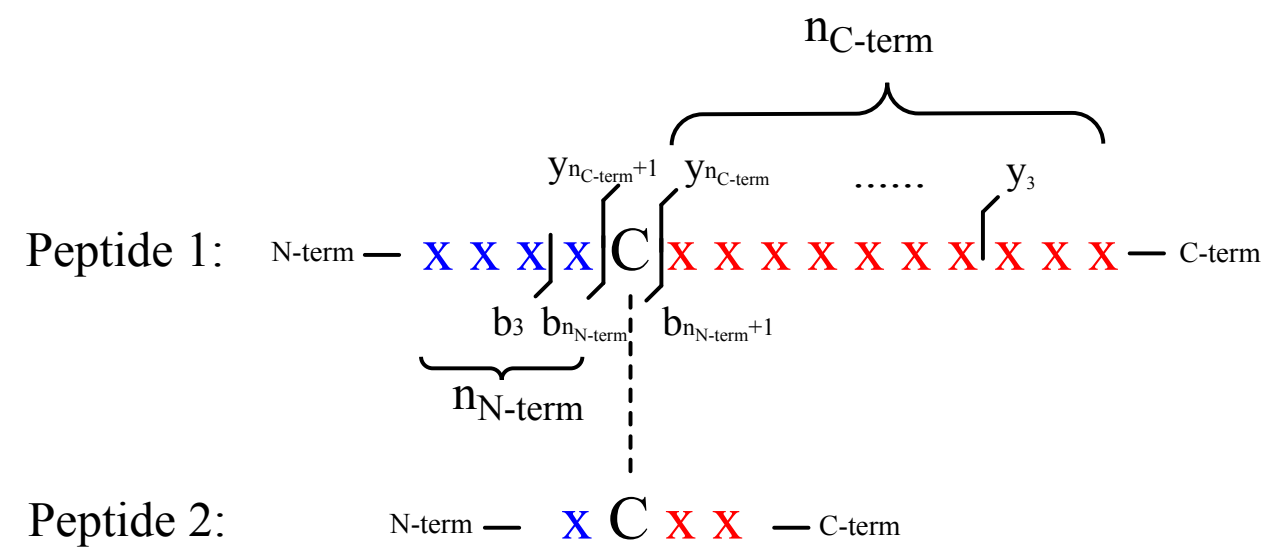

Figure SA Peptide partitioning in disulfide linked two linear peptides for annotation.

Due to the presence of two Cys residues in peptide [115-127] obtained from a fully-cleaved Glu-C $\beta$-LG variant A (and variant B) digest, this peptide can potentially connect another two Cys-containing peptides to form disulfide-linked triple-peptides. During peptide annotation, this di-Cys peptide was divided into three parts ("front", "middle" and "back"), as the "middle" part consisted of Cys119, Phe 120 and Cys121 (Figure SB). 
Peptide 1: $\quad$ N-term - X X X X C X X X X X X X X X X - C-term

Di-Cys peptide:

\section{Peptide 2:}

Figure SB Peptide partitioning in disulfide linked three linear peptides for annotation.

The identification of individual linear components of the cross-linked peptides followed the same rules as described above, where the $\mathrm{m} / \mathrm{z}$ values of both $\mathrm{N}$-term and $\mathrm{C}$-term part of each peptide fragments were compared with the $\mathrm{MS}^{2}$ spectra. However, the exact linker position of tri-peptide disulfide could not be determined, since the "middle" part was not easily cleaved off using the HCD fragmentation setup. Due to distinct hydrophobicity for the two potential pairing modes, two separated peaks are often seen in the extracted ion chromatogram (XIC) with different $\mathrm{LC}$ retention times. In this case, both matched peaks in the XIC are integrated as the sum of the two potential localizations. If one of the Cys on the di-Cys peptide was unpaired, or alkylated, the exact linker location was also not possible to distinguish, presumably due to their similar retention time on the LC column. 

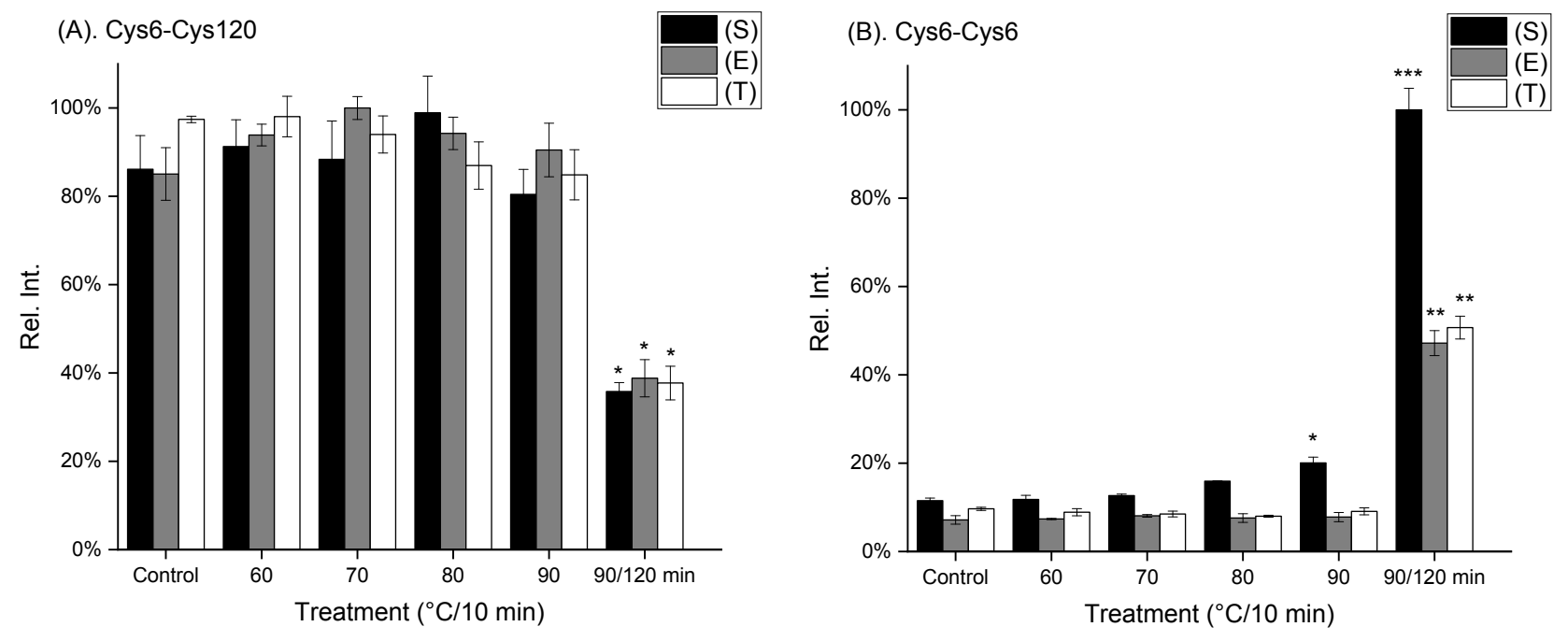

Figure S1 Example of a native (A) Cys6-Cys120, and a non-native, (B) Cys6-Cys6 disulfidelinked $\alpha$-LA peptide signals from LC-MS analysis of three different sample sets: standard set with no alkylation (“S”, black, ?); alkylated exposed free Cys residues ("E”, grey, ?); and alkylated total free Cys residues ("T", white, ?). The applied heat treatments were the same as described for $\beta$-LG in the method section. Asterisks (*) indicate statistically significant between different sample conditions (one-way ANOVA with a Tukey-Kramer HSD post-hoc test, $\mathrm{p}<0.05)$. 
Table S1 The Approximate Peak Areas of Cys-Containing Peptides under Reducing or NonReducing Conditions.*

\begin{tabular}{cc}
\hline Peptide & Approx. intensity \\
\hline Reducing condition: & \\
\hline Cys66 & $300 \times 10^{9}$ \\
Cys106 & $500 \times 10^{9}$ \\
Cys119/Cys121 & $100 \times 10^{9}$ \\
Cys160 & $60 \times 10^{9}$ \\
& \\
\hline Non-reduced condition: & $50 \times 10^{9}$ \\
Cys66 & $4 \times 10^{9}$ \\
Cys106 & $0.4 \times 10^{9}$ \\
Cys119/Cys121 & $6 \times 10^{9}$ \\
Cys160 & $30 \times 10^{9}$ \\
Cys66-Cys66 & $1 \times 10^{9}$ \\
Cys160-Cys160 & $1 \times 10^{9}$ \\
Cys106-Cys106 & $1 \sim 10 \times 10^{6}$ \\
\hline Other non-native disulfides
\end{tabular}

*Peak areas from all detected charge states of the same peptide were summed up at their most abundant signals. In the reducing condition, TCEP (final concentration $13 \mathrm{mM}$ ) and IAA (final concentration $30 \mathrm{mM}$ ) were added and incubated in the dark at $30{ }^{\circ} \mathrm{C}$ sequentially. 
Table S2 Distributions of $\beta$-LG Molecules in Different Aggregated States after Different Heat Treatments from SEC Analysis.*

\begin{tabular}{|c|c|c|c|c|c|c|}
\hline \multirow{2}{*}{ Aggregated state } & \multicolumn{6}{|c|}{ Heat Treatment } \\
\hline & $4^{\circ} \mathrm{C}, 10 \mathrm{~min}$ & $60^{\circ} \mathrm{C}, 10 \mathrm{~min}$ & $70^{\circ} \mathrm{C}, 10 \mathrm{~min}$ & $80^{\circ} \mathrm{C}, 10 \mathrm{~min}$ & $90^{\circ} \mathrm{C}, 10 \mathrm{~min}$ & $90^{\circ} \mathrm{C}, 120 \mathrm{~min}$ \\
\hline Non-native monomer & $\mathrm{N} / \mathrm{A}$ & N/A & N/A & $32.7 \pm 0.4 \% \mathrm{a}$ & $33.1 \pm 0.2 \% \mathrm{a}$ & $21.7 \pm 0.3 \% b$ \\
\hline Native monomer & $97.9 \pm 0.1 \% \mathrm{a}$ & $98.2 \pm 0.0 \% \mathrm{a}$ & $96.6 \pm 0.2 \% b$ & $35.5 \pm 0.5 \% \mathrm{c}$ & $15.7 \pm 0.5 \% \mathrm{~d}$ & $9.3 \pm 0.3 \% \mathrm{e}$ \\
\hline Dimer & $2.1 \pm 0.1 \%$ a & $1.8 \pm 0.0 \% \mathrm{a}$ & $3.4 \pm 0.2 \% \mathrm{~b}$ & $22.8 \pm 0.2 \% \mathrm{c}$ & $33.4 \pm 0.2 \% \mathrm{~d}$ & $27.3 \pm 0.6 \% \mathrm{e}$ \\
\hline Oligomer (<100 kDa) & N/A & N/A & N/A & $7.8 \pm 0.1 \% \mathrm{a}$ & $16.9 \pm 0.4 \% \mathrm{~b}$ & $15.1 \pm 0.2 \% \mathrm{c}$ \\
\hline Polymer (>100 kDa) & N/A & N/A & N/A & $1.1 \pm 0.1 \% \mathrm{a}$ & $0.9 \pm 0.0 \% \mathrm{a}$ & $26.5 \pm 0.6 \% \mathrm{~b}$ \\
\hline
\end{tabular}

*Values in the same row for the same aggregate type followed by different letters are significantly different in different treatments (one-way ANOVA with a Tukey-Kramer HSD post-hoc test, $\mathrm{p}<0.05)$. Abbreviation: N/A, not applicable. 
Table S3 Distributions of $\beta$-LG Molecules in Different Aggregated States after Different Heat Treatments with Addition of Urea from SEC Analysis.*

\begin{tabular}{|c|c|c|c|c|c|c|}
\hline \multirow{2}{*}{ Aggregated state } & \multicolumn{6}{|c|}{ Heat Treatment } \\
\hline & $4^{\circ} \mathrm{C}, 10 \mathrm{~min}$ & $60^{\circ} \mathrm{C}, 10 \mathrm{~min}$ & $7^{\circ} \mathrm{C}, 10 \mathrm{~min}$ & $80^{\circ} \mathrm{C}, 10 \mathrm{~min}$ & $90^{\circ} \mathrm{C}, 10 \mathrm{~min}$ & $90^{\circ} \mathrm{C}, 120 \mathrm{~min}$ \\
\hline Non-native monomer & $33.23 \pm 0.44 \% \mathrm{c}$ & $27.29 \pm 1.64 \% \mathrm{~d}$ & $33.34 \pm 0.79 \% \mathrm{c}$ & $40.06 \pm 0.37 \% \mathrm{a}$ & $36.87 \pm 0.04 \% \mathrm{~b}$ & $25.09 \pm 0.32 \% \mathrm{e}$ \\
\hline Native monomer & $65.23 \pm 0.50 \% \mathrm{~b}$ & $71.48 \pm 1.57 \% \mathrm{a}$ & $62.67 \pm 0.67 \% \mathrm{c}$ & $28.78 \pm 0.59 \% \mathrm{~d}$ & $14.14 \pm 0.28 \% \mathrm{e}$ & $10.22 \pm 0.53 \% \mathrm{f}$ \\
\hline Dimer & $1.53 \pm 0.01 \% \mathrm{e}$ & $1.23 \pm 0.04 \% \mathrm{e}$ & $3.97 \pm 0.28 \% \mathrm{~d}$ & $22.97 \pm 0.23 \% \mathrm{c}$ & $33.75 \pm 0.33 \% \mathrm{a}$ & $31.84 \pm 0.49 \% \mathrm{~b}$ \\
\hline Oligomer (<100 kDa) & $\mathrm{N} / \mathrm{A}$ & N/A & $\mathrm{N} / \mathrm{A}$ & $8.17 \pm 0.02 \% \mathrm{c}$ & $15.23 \pm 0.05 \% \mathrm{~b}$ & $17.94 \pm 0.46 \% \mathrm{a}$ \\
\hline Polymer (>100 kDa) & N/A & N/A & $\mathrm{N} / \mathrm{A}$ & N/A & N/A & $14.85 \pm 0.85 \%$ \\
\hline
\end{tabular}

*Values in the same row for the same aggregate type followed by different letters are significantly different in different treatments (one-way ANOVA with a Tukey-Kramer HSD post-hoc test, $\mathrm{p}<0.05)$. Abbreviation: N/A, not applicable. 